\title{
Neighbourhood crowding severely limits seed offspring recruitment in a temperate mesic old-field meadow
}

\author{
A. Tracey ${ }^{1}$ and L. Aarssen ${ }^{1,2}$ \\ 'Department of Biology, Queen's University, Kingston, ON, Canada K7L 3N6 \\ ${ }^{2}$ Corresponding author.Email: aarssenl@queenwsu.ca
}

Keywords: Competition; Fitness; Neighbour effects; Reproductive economy; Seed addition; Vegetation clearing.

\begin{abstract}
Testing the full impact of neighbourhood crowding within natural vegetation requires more than just effects incurred by established plants. It must also include measurements that take into account suppressive effects on the earliest plant life stages of resident individuals - seeds, their germination (emergence of radicles and cotyledons), and very young rooted seedlings. In this study, we explored the potential for these effects in a field experiment spanning three years, using a novel design for controlling granivory and small mammal herbivory. This allowed us to assess the limitations of natural crowding on seed recruitment success for non-resident species introduced into both natural and denuded neighbourhood plots within a temperate mesic old field meadow in eastern Ontario, Canada. Our results show that crowding by standing vegetation of resident species caused an overall reduction of seed recruitment success by more than $90 \%$. These data provide strong inference that suppression resulting directly from near neighbour effects are likely to impose routinely intense natural selection within temperate mesic old field habitats like our study site. The consequences of this selection, in terms of traits promoting plant fitness under competition, are traditionally interpreted in terms of superior resource depletion/uptake, typically associated with greater growth accumulation and larger potential body size. We suggest, however, that these consequences are rare. Individuals of any species approach maximum potential body size only when near neighbour effects are relatively weak - not within crowded neighbourhoods. Recent studies suggest that severe neighbourhood crowding (where virtually all resident plants are forced to remain relatively small) selects instead for 'reproductive economy' - i.e., capacity to produce at least a few (or even at least one) offspring despite severe body size suppression, involving a relatively small minimum reproductive threshold size. Potential for additional component traits of reproductive economy are also suggested for investigation in future research.
\end{abstract}

Nomenclature: Gleason and Cronquist (1991).

\section{Introduction}

Neighbourhood crowding, and the competition for limited resources that it imposes, is commonly regarded as an intense force of natural selection within natural vegetation. This of course implies that crowding routinely limits establishment, survival, growth, and/or reproduction for some resident individuals/genotypes more than others - and so causes differential transmission of genes/alleles (and hence expression of their phenotypic consequences) within future generations. A large body of published research, interpretation, and debate has explored the intensity and importance of this selection process and the potential fitness consequences of associated phenotypic traits (e.g., Aarssen 1989, Aarssen and Epp 1990, Grace 1990, Aarssen 1992, Goldberg and Barton 1992, Gurevitch et al. 1992, Goldberg 1996, Miller 1996, Aarssen and Keogh 2002, Aarssen 2008, Damgaard and Fayolle 2010, Kikvidze and Brooker 2010, Thorpe et al. 2011, Brooker et al. 2013, Trinder et al. 2013, Aarssen 2015).

Based on these and other previous studies, there is now abundant evidence to conclude that suppressive neighbour effects on survival, growth and reproduction of resident plants are routinely significant within natural vegetation. There is less certain empirical evidence, however, regarding the impact of neighbour effects on the fates of individual resident seeds. In other words, does neighbourhood crowding (i.e., denial of contested resources because of the presence of neighbouring plants) significantly limit the probability that a seed residing there will be recruited successfully? Some supporting evidence for this limitation is suggested by previous seed addition and gap colonization/regeneration studies (e.g., Burke and Grime 1996, Foster 1999, Bullock 2000, Jutila and Grace 2002, Kleijn 2003). A number of other potential 'habitat filters', however, might (independent of neighbour effects) also impose limitations at several stages of establishment e.g., seed loss to leaching, granivory or fungal attack; seed germination failure because of unsuitable local physio-chemical micro-environmental conditions for initiating seed germination; seedling or juvenile mortality because of herbivory, pathogens, disease, soil microbial / mycorrhizal limitations, or because of resource deprivation (e.g., drought, impoverished soil nutrients) or environmental toxicity. Without being controlled in experimental studies, therefore, these effects may limit or confound the interpretation of neighbour effects.

From a review of several previous studies that recorded natural establishment from seed following major disturbances (causing loss of standing vegetation), Moles and Westoby (2004) discovered that virtually all of the seedling mortality for resident species resulted from herbivory, drought or fungal attack; mortality caused by seedling-seedling competition 
Table 1. List of the 46 collected species (and life history category) that were added as seeds to the experimental field plots.

\begin{tabular}{llll}
\hline Achillea millefolium & perennial & Lapsana communis & annual \\
Anaphalis margaritacea & perennial & Lepidium campestre & biennial \\
Antennaria neglecta & perennial & Lotus corniculatus & perennial \\
Aquilegia canadensis & perennial & Lychnis alba & annual \\
Arenaria serpyllifolia & annual & Matricaria matricarioides & annual \\
Aster umbellatus & perennial & Medicago lupilina & annual \\
Barbarea vulgaris & biennial & Melilotus alba & biennial \\
Brassica nigra & annual & Mentha piperita & perennial \\
Chaenorrhinum minus & annual & Oenothera biennis & biennial \\
Chicorium intybus & perennial & Penstemon hirsutus & perennial \\
Cynoglossum officinale & perennial & Plantago major & perennial \\
Daucus carota & biennial & Potentilla argentea & perennial \\
Dianthus armeria & biennial & Rumex acetosella & perennial \\
Dianthus deltoids & perennial & Rumex crispus & perennial \\
Erigeron canadensis & annual & Saponaria officinalis & perennial \\
Erigeron strigosus & annual & Silene cucubalus & perennial \\
Eupatorium maculatum & perennial & Smilacina racemose & perennial \\
Geranium maculatum & annual & Sonchus arvensis & perennial \\
Geranium robertanium & perennial & Sonchus oleraceus & annual \\
Helianthus divaricatus & perennial & Trifolium hybridum & perennial \\
Hespersis matronalis & biennial & Tussilago farfara & perennial \\
Hieracium canadense & annual & Verbascum thapsus & biennial \\
Lactuca serriola & annual & Veronica serpyllifolia & perennial \\
\hline
\end{tabular}

was essentially negligible. By comparison, effects of established plants on seed offspring recruitment within crowded neighbourhoods are likely to be far from negligible in most vegetation, but these effects are notoriously difficult to quantify. Recruitment success for introduced species, however, is more easily accounted for experimentally, and can therefore be used as a surrogate to estimate the intensity of selection (i.e., failed recruitment) on the seed offspring of resident species. Accordingly, we conducted a field experiment spanning three years, using a novel design for controlling effects of granivory and small mammal herbivory in order to test for specific effects of natural crowding on seed recruitment success for non-resident species introduced into both natural and denuded neighbourhood plots within a temperate mesic old field meadow in eastern Ontario, Canada.

\section{Materials and methods}

Study site

The study was conducted between 2013 and 2016 at the Queen's University Biological Station (QUBS) near Chaffey's Locks, Ontario, Canada (443' N, $\left.76^{\circ} 21^{\prime} \mathrm{W}\right)$, using an old field meadow on a section of QUBS land known locally as the Bracken tract. The climate is temperate mesic with mean annual precipitation (1981-2010) of $950 \mathrm{~mm}$ (based on data from the weather station at nearby Kingston; ECCC 2017), and the soil is clay loam. The field is rectangular, roughly $150 \mathrm{~m} \times 200 \mathrm{~m}$, and surrounded by a mix of shrubland and mature woodland. The field was last tilled and sown (with an unknown forage seed mix) sometime in the early half of the last century, and was used periodically for light cattle grazing and occasional hay harvest until 2010. A survey of the field in 2010 recorded 52 resident species (Appendix A1).

\section{Selection of introduced species}

In the summer field season of 2013, seeds were collected from wild herbaceous vegetation near QUBS for as many species ( $n=46$; Table 1$)$ as were encountered during haphazard field excursions and as time permitted. Species were chosen that are at least occasionally found in old field habitats, but also (and in some cases more commonly) found in more recently disturbed (e.g., roadside) habitats - but only species not already resident within the Bracken old field. At least 40,000 seeds (from one or several populations combined) were collected for each species and kept in paper bags stored at ambient (room) temperature until December (2013) when they were placed within experimental field plots (protected from granivory and from physical disturbance by wind and water) - described below - in order to allow breaking of dormancy under natural overwintering conditions.

\section{Field plot installation}

Circular experimental plots $(\mathrm{n}=200), 60 \mathrm{~cm}$ in diameter $\left(0.28 \mathrm{~m}^{2}\right)$, were positioned in three rows (4 $\mathrm{m}$ apart), with adjacent plots separated by $2 \mathrm{~m}$, and assigned (alternately) to one of two treatments (with 100 replicate plots each): natural vegetation plots and denuded plots (with all resident plants removed). For the denuded plots, the perimeter was trenched to a depth of approximately $20 \mathrm{~cm}$ using a spade, and a cir- 
cular metal sleeve (cylinder) was inserted into the trench to exclude (from the plot) the spread of roots and rhizomes of plants growing outside the plots. The sleeves were made of aluminum flashing $-60 \mathrm{~cm}$ in diameter and $25 \mathrm{~cm}$ high and were installed within the trenches to a depth of $20 \mathrm{~cm}$, leaving $5 \mathrm{~cm}$ above ground.

In September 2013, vegetation within the cylinder plots was cut down to $15 \mathrm{~cm}$ in height to stimulate new growth (and clippings were discarded). After two weeks, the broad-spectrum systemic herbicide Roundup (Glyphosate - Monsanto Canada) was applied to the vegetation carefully using a spray bottle and was re-applied two weeks later to ensure complete mortality of resident plants. Once all vegetation was brown, the standing dead plants were clipped at ground level, and the clippings and other plant litter within the plot were collected and discarded. The natural vegetation plots were left undisturbed and were marked (for re-location) by inserting four coloured spikes into the ground, equidistant apart from each other along the circular plot perimeter (diameter $60 \mathrm{~cm}$ ), using a circular quadrat as a guide, positioned directly above the plot.

\section{Addition of introduced species}

In the fall of 2013, 200 seeds of each of the 46 introduced species $(9,200$ seeds in total) were placed into each of 200 packets made of porous drapery material, measuring $15 \mathrm{~cm}$ $\times 20 \mathrm{~cm}$ and sown around the edges. In December 2013, two seed packets were placed flat on the soil surface within each denuded (cylinder) plot, and fixed there using long pins inserted into the ground. The seeds were left there to overwinter in situ. To ensure seeds were safe from granivory by small mammals and birds, lids made of aluminum flashing edges and wire mesh covers (with $0.5 \mathrm{~cm} \times 0.5 \mathrm{~cm}$ openings) were attached to the cylinders. Because the seeds were contained within the packets, fixed to the soil surface, they were prevented from being disturbed and moved around within the plot by wind or heavy precipitation/snow melt over the winter.

To estimate seed germinability under field conditions, seed samples for each of the introduced species were placed within 'micro-germination' chambers in December 2013 and left to overwinter at the field site. These chambers were constructed from craft 'bead boxes' involving individual cells (each $4 \mathrm{~cm} \times 6 \mathrm{~cm}$ ) with snap lids. A $2.5 \mathrm{~cm}$ hole was drilled in the lid and bottom of each cell for allowing natural precipitation to pass through. Two layers of porous and colourless felt were glued to the bottom of each cell, and porous drapery material was glued on the inside of the lid to cover the top hole and thus ensure that no seeds could escape during potential splashing from heavy precipitation. Each species was assigned 12 replicate cells with 25 seeds added per cell. Twelve bead boxes were installed in each of 8 replicate wooden boxes with hardware mesh (with $0.25 \mathrm{~cm}^{2}$ openings) installed on the top and bottom to exclude small mammals and with landscape fabric covering the bottom. The 8 wooden boxes were placed on the soil surface and distributed evenly throughout the field site, with exclosure fencing (1.5 m high) installed around the perimeter of each box to prevent whitetailed deer and other animals from walking on the boxes over the winter. Smaller scale tests of these micro-germination chambers, carried out in the lab, ensured that none of the construction materials affected seed germination.

In early spring (mid-March) of 2014, after snow melt, the micro-germination chambers were visited every 2-3 days to score germination by recording the number of seeds with, at minimum, a radicle emerging. These data were then used to calculate the expected percent germination success (estimated 'germinability') of each species within the experimental plots.

Also early in spring (April 18), 2014 (and before evidence of seed germination within the germination chambers), the two seed packets were retrieved from each denuded (cylinder) plot and the contents of one was sown back into the plot, while the contents of the other was sown into an adjacent natural vegetation plot. Sowing for each plot involved emptying the contents of the packet (200 seeds of each of the 46 species) into a sieve containing a small sample of dry sand to distribute the packet contents evenly while waving the sieve over the plot to ensure random and even distribution of seeds. The lids were then returned to the denuded plots to prevent granivory and seedling herbivory, and were removed again once juvenile plants were established and starting to touch the hardware mesh lids. Lids were then replaced with hardware mesh fencing (with $0.25 \mathrm{~cm}^{2}$ openings) - $1 \mathrm{~m}$ high and trenched $5 \mathrm{~cm}$ into the ground, surrounding each plot to exclude white-tailed deer and prevent small mammals and birds from consuming seedlings or un-germinated seeds. The same hardware mesh fencing was installed around the natural vegetation plots as soon as the seeds were sown. This fencing remained in place for the duration of the study, except when temporarily removed during plot sampling.

\section{Plot sampling}

During August in the summers of 2014, 2015, and 2016, the number of rooted individuals were counted and recorded for each introduced species within each plot.

\section{Results}

The introduced species varied widely in estimated seed germinability in spring 2014 after overwintering in situ (Fig. 1 ), with an overall germinability (across all species) of $20 \%$ for the total number of seeds of introduced species sown in the spring of 2014 - amounting to approximately 181,200 germinable seeds in total across the 100 denuded plots (ca. 6470 seeds per $\left.\mathrm{m}^{2}\right)$. In 2014, 1.3\% of the latter (2,262 individuals) emerged as resident plants across the 100 denuded plots, equivalent to 81 individuals counted per $\mathrm{m}^{2}$, and represented by 26 of the 46 introduced species (Fig. 2).

Estimated seed germinability in 2014 showed no relationship to species abundance counts in either the denuded plots, or the natural vegetation plots in any of the three census years (Fig. 1). Factors other than our seed germinability 
estimates, therefore, account for the between-species variation in recruitment success. The most striking results concern the very large effect sizes of our experimental treatment. Compared with counts recorded in denuded plots, neighbourhood crowding from the standing vegetation of resident species in the natural vegetation plots caused an overall reduction in seed recruitment success by $95 \%$ in the 2014 census (Fig. 2), 97\% in the 2015 census (Fig. 3), and 95\% in the 2016 census (Fig. 4). For species that had at least one resident plant recorded in both treatments, the mean reduction in seed recruitment success was $93 \%, 90 \%$, and $92 \%$ respectively for census counts recorded in 2014 (Fig. 2c), 2015 (Fig. 3c) and
2016 (Fig. 4c) respectively. Several species (4 in 2014, 4 in 2015, and 5 in 2016) had counts exceeding 50 individuals in the denuded plots but had zero individuals recorded in the natural vegetation plots.

\section{Discussion}

Why do the vast majority of individuals within natural vegetation die without sex? The answer to this question defines the forces of natural selection that have shaped the phenotypes of plant biotas everywhere. The traditional Darwinian view is that much, if not most of this failure is
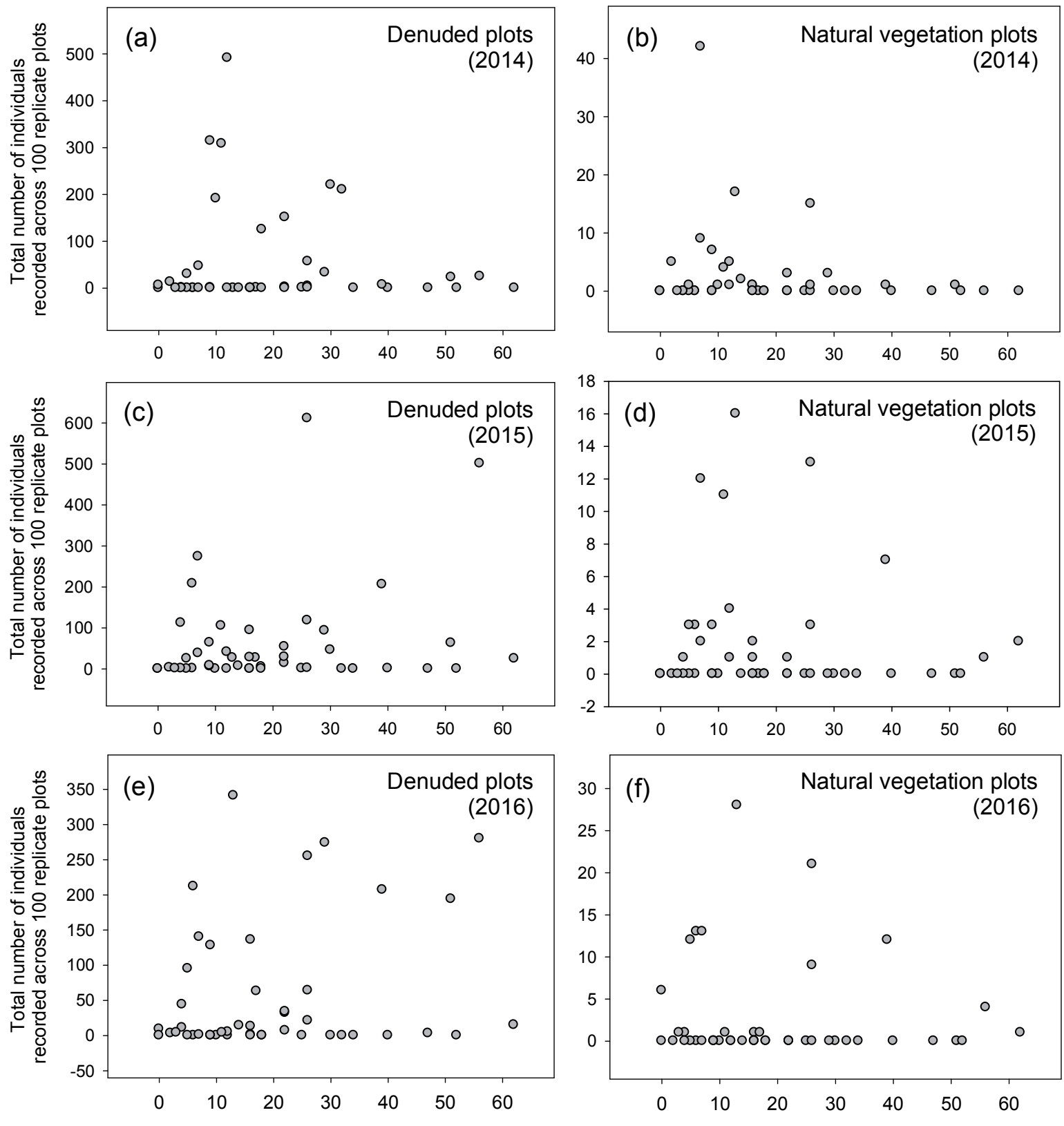

Percent seed germinability recorded in 2014

Percent seed germinability recorded in 2014

Figure 1. Scatterplots for percent seed germinability of introduced species $(n=46)$, recorded in 2014, versus their total census counts recorded in denuded plots and natural vegetation plots in 2014 (a, b), in 2015 (c, d), and in 2016 (e, f). All plots have the same x- and $\mathrm{y}$-axes, but note the much larger $\mathrm{y}$-axis scales in denuded plots (a, c, e) compared with natural vegetation plots (b, d, f). 
an inevitable consequence of the intrinsic capacity in all species for geometric increase in population size, combined with a relentlessly limited supply of locally contested resources (Darwin 1859, Harper 1977). Many previous studies involving experimental field plots, including in old fields, have shown that removal of near neighbours routinely results in 'competitive release' of remaining established ('target')
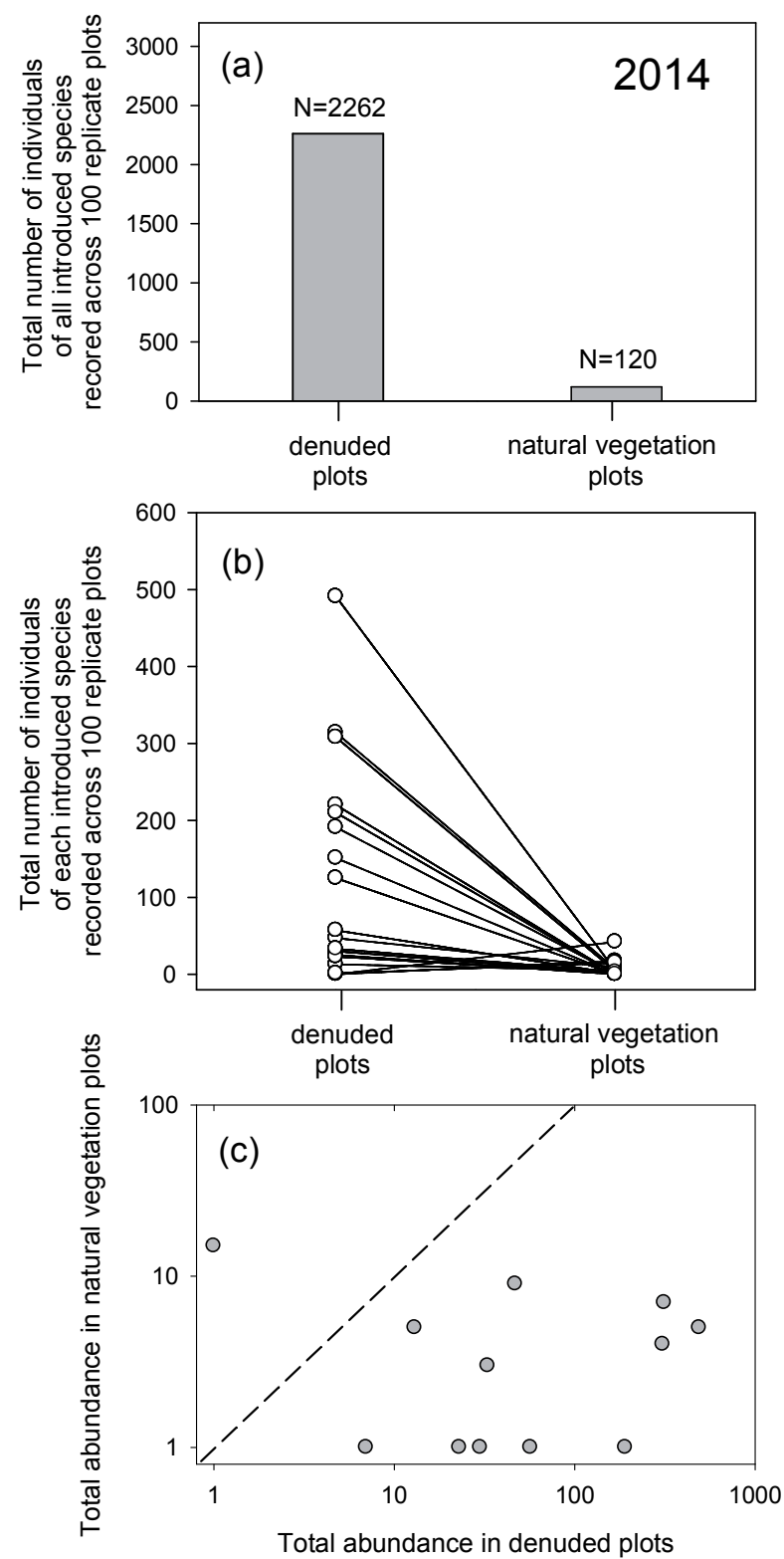

Figure 2. Comparison of total recruitment success (number of resident plants) recorded in year one (2014) - the year of seed addition to natural vegetation plots $(\mathrm{n}=100)$ versus denuded plots $(n=100)$ : (a) for all introduced species combined $(n=26)$ that had at least 1 resident plant; (b) for each introduced species $(n=18)$ that had at least ten resident plants recorded within at least one of the two treatments; and (c) for each introduced species $(n=12)$ that had at least one resident plant recorded in both treatments; dashed line in (c) is for reference only, to indicate where ' $y$ ' would equal ' $x$ ' (note log scales) (Wilcoxon signed rank test: $\mathrm{P}=0.002$ ). plants - i.e., resulting in significantly greater growth and/ or reproduction compared with control (natural vegetation) plots (e.g., Aarssen and Epp 1990, Taylor and Aarssen 1990, Goldberg and Barton 1992, Gurevitch et al. 1992). But conclusive evidence based on effect sizes from controlled experiments, has remained largely elusive for measuring the full impact of neighbourhood crowding in natural vegetation that
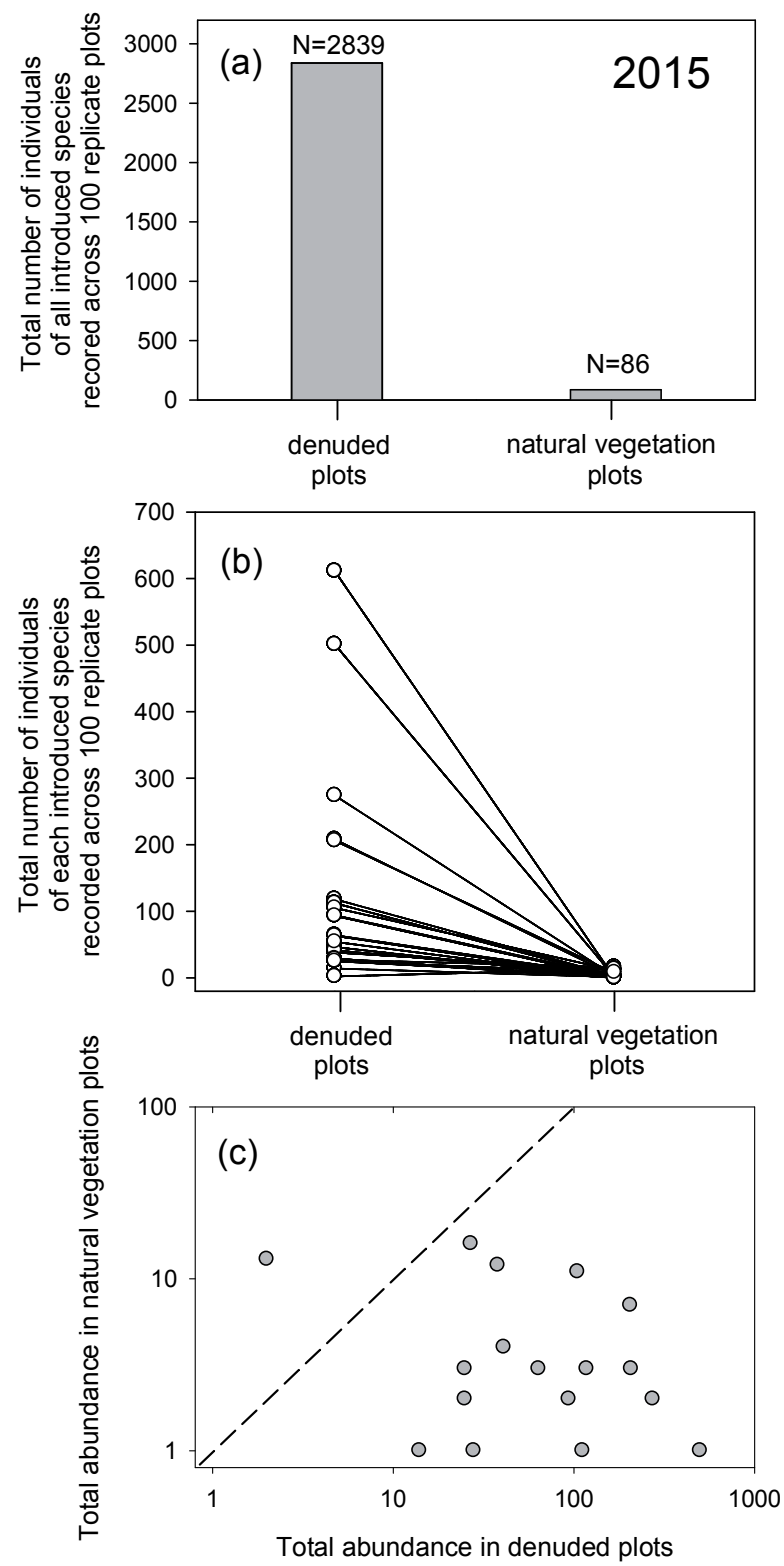

Figure 3. Comparison of total recruitment success (number of resident plants) recorded in year two (2015) following seed addition (in 2014) to natural vegetation plots $(\mathrm{n}=100)$ versus denuded plots $(\mathrm{n}=100)$ : (a) for all introduced species combined $(\mathrm{n}=$ 35 ) that had at least 1 resident plant; (b) for each introduced species $(n=24)$ that had at least ten resident plants recorded within at least one of the two treatments; and (c) for each introduced species $(n=17)$ that had at least one resident plant recorded in both treatments; dashed line in (c) is for reference only, to indicate where ' $y$ ' would equal ' $x$ ' (note log scales) (Wilcoxon signed rank test: $\mathrm{P}<0.001)$. 
includes the earliest plant life stages of resident individuals - seeds, their germination (emergence of radicles and cotyledons), and very young rooted seedlings (Aarssen and Keogh 2002). By using non-resident (introduced) species, however, where relative seed recruitment success can be more easily enumerated, combined with exclosures to prevent granivory and small mammal seedling herbivory, our results for a tem-
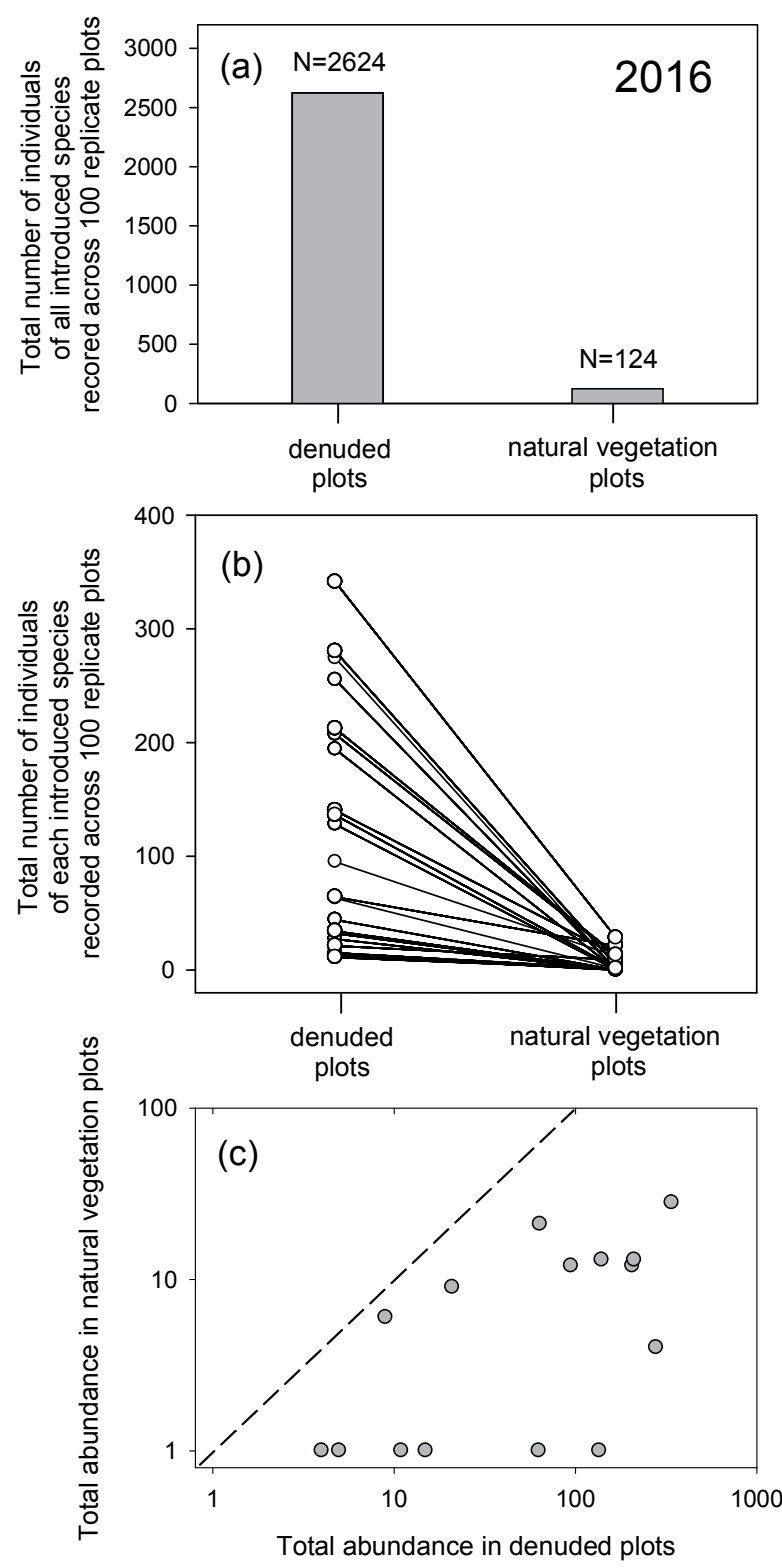

Figure 4. Comparison of total recruitment success (number of resident plants) recorded in year three (2016) following seed addition (in 2014) to natural vegetation plots $(n=100)$ versus denuded plots $(\mathrm{n}=100)$ : (a) for all introduced species combined $(\mathrm{n}=30)$ that had at least 1 resident plant; (b) for each introduced species $(n=21)$ that had at least ten resident plants recorded within at least one of the two treatments; and (c) for each introduced species $(n=15)$ that had at least one resident plant recorded in both treatments; dashed line in (c) is for reference only, to indicate where ' $y$ ' would equal ' $x$ ' (note log scales) (Wilcoxon signed rank test: $\mathrm{P}<0.001$ ). perate mesic old field meadow indicate that natural levels of crowding by standing vegetation of resident species caused on overall reduction of seed recruitment success by more than 90\% (Figs. 2-4).

These data infer, therefore, that because of this natural neighbourhood crowding, the seed offspring of resident species at our study site are also likely to suffer severe mortality rates as germinating seeds, seedlings and juveniles (as well as possibly reduced seed germination success). Individual seedling / juvenile survival (and seed germination success) will of course be affected by local physical/chemical microenvironments - and these will be very different in a crowded plant neighbourhood compared with a denuded neighbourhood - precisely because of the absence, in the latter, of crowded standing vegetation. Nevertheless, our removal of neighbour effects (in denuded plots) resulted in more than 10 -fold greater recruitment success of individuals from seed - this despite that effects of soil litter accumulation within plant neighbourhoods (and effects of their shading canopies) may actually promote recruitment by reducing effects of desiccation on seedling mortality (e.g., Fayolle et al. 2009, Knappova et al. 2013), or possibly by reducing visibility to granivores (although we controlled for possible effects of the latter using wire mesh exclosures).

We cannot discount the possibility that recruitment success for our introduced species may have been partially limited (or strongly limited for some species) in our crowded natural vegetation plots because of greater limitations there (independent of neighbour effects) involving seedling / juvenile mortality because of insect herbivory, pathogens, disease, or soil microbial/mycorrhizal limitations. By the same token, we cannot discount the possibility that recruitment success, for some introduced species, may have been promoted in denuded plots by facilitation effects from certain resident species also emerging there (at the same time) from the seed bank. We have no reason, however, to speculate that impact from any of these potential effects is likely to have been greater in our natural vegetation plots than in the denuded plots, positioned only $2 \mathrm{~m}$ apart from each other.

On balance, our results, we suggest, provide strong inference that suppressing effects resulting directly from natural crowding (including potential shading effects from neighbourhood litter) are likely to impose routinely intense natural selection within temperate mesic old-field habitats like our study site. Note that even in our denuded plots (although we could not measure its intensity), seedlings and juveniles of introduced species were visibly crowded and suppressed by each other and by the many seedlings and juveniles of resident species also emerging at the same time, from the soil seed bank, and competing for neighbourhood resources over the three-year study period.

These findings invite an obvious question for future research emphasis: What are the consequences of this intense selection pressure within natural vegetation? In other words, what are the functional traits that enable some resident species to leave more descendants (and hence have greater abundance) compared with others, or that enable only certain spe- 
cies to persist here, despite neighbourhood crowding? The traditional interpretation for greater success under resource competition involves superior capacity to deny contested resources to neighbours, through more effective resource uptake/depletion, typically associated with greater growth accumulation and larger attainable body size (Grime 1979, Keddy 1989, Grace 1990, Goldberg 1996, Thorpe et al. 2011, Aschehoug et al. 2016, Hart et al. 2018). But this is unlikely within natural vegetation; the maximum potential body sizes (MAX) of resident species here are attainable only in relatively uncrowded neighbourhoods. All species that grow within a severely crowded neighbourhood (which typically include conspecific neighbours) are necessarily severely suppressed, if not virtually expired. Having a relatively large MAX provides no advantage here. Successful offspring production instead requires 'reproductive economy' (sex before death) - i.e., capacity to produce at least one offspring despite severe body size suppression, and hence a high fecundity allocation (number of offspring per unit plant size per unit time) (Aarssen 2008, 2015). Interpretation of the components of reproductive economy, we suggest, will require future studies with particular focus on effects resulting from (i) a relatively small minimum reproductive threshold size (Tracey and Aarssen 2014, 2018); (ii) relatively small seed size (Aarssen 2005), (iii) offspring production through clonality (Aarssen 2008); (iv) a relatively high body mass density (hence fecundity per unit plant body space occupancy) (Tracey et al. 2016); and (v) relatively high leafing intensity (associated with relatively small leaf mass) and hence larger bud bank (number of axillary meristems per unit plant body size) available for deployment as flowers/fruits — and thus, higher potential fecundity allocation (Dombroskie et al. 2016).

Acknowledgements: Assistance with field work was provided by A. Deveto, A. Dudas, E. Irwin, Y. Jinoui, J. Macmillan, E. Morris, M. Perret, J. Serafini, A. Sprott and K. Stephens. This research was supported by the Natural Sciences and Engineering Council of Canada through a discovery grant to L.W.A.

\section{References}

Aarssen, L.W. 1989. Competitive ability and species coexistence: a 'plant's eye' view. Oikos 56:386-401.

Aarssen, L.W. 1992. Causes and consequences of variation in competitive ability in plant communities. J. Veg. Sci. 3:165-174.

Aarssen, L.W. 2005. Why don't bigger plants have proportionately bigger seeds? Oikos 111:199-207.

Aarssen, L.W. 2008. Death without sex - the 'problem of the small' and selection for reproductive economy in flowering plants. Evol. Ecol. 22:279-298.

Aarssen, L.W. 2015. Body size and fitness in plants: revisiting the selection consequences of competition. Perspect. Plant Ecol. Evol. Syst. 17:236-242.

Aarssen, L.W. and G.A. Epp. 1990. Neighbour manipulations in natural vegetation: a review. J. Veg. Sci. 1:13-30.

Aarssen, L.W. and T. Keogh. 2002. Conundrums of competitive ability in plants: what to measure? Oikos 96:531-542.
Aschehoug, E.T., R. Brooker, D.Z. Atwater, J.L. Maron and R.M. Callaway. 2016. The mechanisms and consequences of interspecific competition among plants. Annu. Rev. Ecol, Evol. Syst. 47:263-281.

Brooker, R., Z. Kikvidze, G. Kustler, P. Liancourt and M. Seifan, 2013. The concept and measurement of importance: a comment on Rees et al. 2012. J. Ecol. 101:1369-1378.

Bullock, J. 2000. Gaps and seedling colonization. In: Fenner M (ed) Seeds: The Ecology of Regeneration in Plant Communities, $2^{\text {nd }}$ ed. CABI Publishing, Wallingford, UK. pp. 375-396.

Burke M.J.W. and J.P Grime. 1996. An experimental study of plant community invasibility. Ecology 77:776-790.

Damgaard, C. and A. Fayolle.. 2010. Measuring the importance of competition: a new formulation of the problem. J. Ecol. 98:1-6.

Darwin, C. 1859. On the Origin of Species. Murray, London.

Dombroskie, S.L., A.J. Tracey and L.W. Aarssen. 2016. Leafing intensity and the fruit size/number trade-off in woody angiosperms. J. Ecol. 104:1759-1767.

ECCC - Environment and Climate Change Canada. 2017. Canadian Climate Normals 1981-2010 Station Data. Retrieved September 13, 2017, from http://climate.weather.gc.ca/climate normals/ results_1981_2010_e.html?searchType $=$ stnName\&txtStationN ame $=$ Kingston $\&$ searchMethod $=$ contains $\&$ txtCentralLatMin $=0$ \& txtCentralLatSec $=0 \&$ txtCentralLongMin $=0 \&$ txtCentralLongS $\mathrm{ec}=0 \& \operatorname{stn} I \mathrm{D}=4300 \&$ dispBack $=1$

Fayolle, A., C. Violle and M.L. Navas. 2009. Differential impacts of plant interactions on herbaceous species recruitment: disentangling factors controlling emergence, survival and growth of seedlings. Oecologia 159:817-825.

Foster, B. 1999. Establishment, competition and the distribution of native grasses among Michigan old-fields. J. Ecol. 87:476-489

Gleason, H.A. and A. Cronquist. 1991. Manual of the Vascular Plants of North-eastern United States and Adjacent Canada. The New York Botanical Garden, Bronx, NY, USA

Goldberg, D.E. 1996. Competitive ability: definition, contingency and correlated traits. Philos. Trans. R. Soc. Lond. B 351:13771385 .

Goldberg, D.E. and A.M. Barton. 1992. Patterns and consequences of interspecific competition in natural communities: a review of field experiments with plants. Am. Nat. 139:771-801.

Gurevitch, J., L.L. Morrow, A. Wallace and J.S. Walsh. 1992. A meta-analysis of competition in field experiments. Am. Nat. 140:539-572.

Grace, J. B. 1990. On the relationship between plant traits and competitive ability. In: Grace, J. B. and Tilman, D. (eds), Perspectives on Plant Competition. Academic Press, New York. pp. 51-65.

Grime, J.P. 1979. Plant Strategies and Vegetation Processes. Wiley, New York

Harper, J.L. 1977. Population Biology of Plants. Academic Press, London.

Hart, S.P., R.P. Freckleton and J.M. Levine. 2018. How to quantify competitive ability. J. Ecol. 106:1902-1909.

Jutila, H.M. and J.B. Grace. 2002. Effects of disturbance on germination and seedling establishment in a coastal prairie grassland: a test of the competitive release hypothesis. J. Ecol. 90:291-302.

Keddy, P.A. 1989. Competition. Chapman and Hall, London.

Kikvidze, Z. and R. Brooker. 2010. Towards a more exact definition of the importance of competition - a reply to Freckleton et al. (2009). J. Ecol. 98:719-724. 
Kleijn, D. 2003. Can establishment characteristics explain the poor colonization success of late successional grassland species on ex-arable land? Restor. Ecol. 11:131-138.

Knappova, J., M. Knapp and Z. Munzbergova. 2013. Spatiotemporal variation in contrasting effects of resident vegetation on establishment, growth and reproduction of dry grassland plants: Implications for seed addition experiments. PLOS ONE 8(6):e65879.

Miller, T. E. 1996. On quantifying the intensity of competition across gradients. Ecology 77:978-981.

Moles, A.T. and M. Westoby. 2004. What do seedlings die from and what are the implications for evolution of seed size? Oikos 106: 193-199.

Taylor, D.R. and L.W. Aarssen. 1990. Complex competitive relationships among genotypes of three perennial grasses: implications for species coexistence. Am. Nat. 136:305-327.

Thorpe, A.S., E.T. Aschehoug, D.Z. Atwater and R.M. Callaway. 2011. Interactions among plants and evolution. J. Ecol. 99:729740 .

Tracey, A.J. and L.W. Aarssen. 2014. Revising traditional theory on the link between plant body size and fitness under competition: evidence from old-field vegetation. Ecol. Evol. 4:959-967.
Tracey, A.J., and L.W. Aarssen. 2018. Resident species with larger size metrics do not recruit more offspring from the soil seed bank in old-field meadow vegetation. J. Ecol. (in press).

Tracey, A.J., K.A. Stephens, B.S. Schamp and L.W. Aarssen. 2016. What does body size mean, from the "plant's eye view"? Ecol. Evol. 6:7344-7351.

Trinder, C.J., R.W. Brooker and D. Robinson. 2013. Plant ecology's guilty little secret: understanding the dynamics of plant competition. Funct. Ecol. 27, Special Issue SI:918-929.

Received September 5, 2018

Revised November 4, 2018

Accepted November 19, 2018

\section{Supplementary material}

Appendix A1. List of 52 species recorded at the Bracken field site in 2010 .

The appendix may be downloaded from www.akademiai. com. 